\title{
Chyle Leak Post Pancreatic Resection. When and why of Etiopathogenesis and how of Management
}

\author{
Norman Oneil Machado* \\ Department of Surgery, Sultan Qaboos University hospital, Muscat, OMAN
}

Received: September 09, 2015; Accepted: November 15, 2015; Published: December 02, 2015

*Corresponding author: Norman Oneil Machado, Department of Surgery, Sultan Qaboos University hospital, Muscat, OMAN, PO Box: 28, Postal code: 123, Tel: 0-96-8 99-432723; Email: oneilnorman@gmail.com

\begin{abstract}
Introduction: Pancreatic resections are associated with significant morbidity. While most of the complications are well documented in the literature, chyle leak gets scant attention. The aim of this article is to review the etiopathogenesis and management of chyle leak post pancreatic resection.

Methods: A medline search of major articles in English literature of 2 or more cases of chyle leak and ascites were reviewed and the findings analysed.

Results: A total of 8 studies were identified comprising of 5564 cases of pancreatic resections. Chyle leak was reported in $4.11 \%$ of these cases. Associated surgical procedures included, vascular resection and reconstruction in 36\%, visceral resection in $44 \%$, standard lymph node dissection in $59 \%$ and para-aortic manipulation. An average of 14.6 lymph nodes were harvested. Early enteric feeding was employed in $58 \%$. The leak was noted at median postoperative period of 6 days. Most of the patients were managed conservatively with NPO, octreotide and in some cases TPN, followed by medium chain or low chain triglycerides, once the amount of leak reduced. Diagnostic paracentesis, lymphiscintigraphy, lymphangiogram, reexploration and ligation of leaking lymphatic vessels andperitoneol venous shunt were carried out in limited number of cases. Associated post operative complications included pancreatic fistula, intraabdominal abscess, sepsis, portal vein thrombosis, delayed gastric emptying. The mean time of discharge was 15 days post surgery.

Conclusions: chyle leak is a rare complication following pancreatic resection. Factors predictive of chyle leak include increasing number of lymph nodes harvested, concomitant vascular resection and visceral resection and early enteral feeding. Majority of them are managed conservatively.
\end{abstract}

Key words : chyle leak, chyle ascites, pancreaticoduodenectomy, pancreatic resections

\section{Introduction}

Chylous discharge following abdominal surgery is uncommon and its etiopathogenesis, diagnosis and management are poorly described. However, several reports in the recent past acknowledge this complication, following aggressive pancreatic resection for malignancy, in the quest to attain a R0 resection [1-11].Chyle leak over a prolonged period of time may render the patient susceptible for infection related complications, as the lymphatic fluid contains lymphocytes and immunoglobulins and loss of fluid could result in lymphocytopenia and immune deficiency $[12,13]$. Moreover, they are at the risk of developing malnutrition, wound related complications, sepsis, prolonged hospitalstay and perioperative mortality $[1,9,10,12,13]$. This article intends to review the literature and address the issue of diagnosis, in addition to when and why does chyle leak occur and how is it managed. Also discussed are intra-operative measures to detect chyle leak and discuss the proposed grading of the chyle leak reported in the literature.

\section{Literature review}

A medline search of major articles in English literature, of 2 or more cases of chyle leak and ascites were carried out, using the search word chyle leak, chyle ascites, pancreaticoduodenectomy, distal pancreatectomy and pancreatic resections. The articles were scrutinized for details of definition, nature of surgery, incidence, associated procedure including vascular resection, adjoining visceral resection, number of lymph nodes harvested and extent of lymphadenectomy. The post operative course with regards to the day of leak, amount of leak, day of enteral feeding, postoperative complications, management and day of discharge was noted.

Results-A total of 8 studies were identified comprising of 5564 cases of pancreatic resections. Some articles did not discussall the various variables studied (table1 and 2) and hence the data presented here are from the data reported inseries studied. Chyle leak was observed in $4.11 \%$ of these cases. Associated surgical procedures included, vascular resection and reconstruction in $36 \%$, visceral resection in $44 \%$, standard lymph node dissection in $59 \%$ and para-aortic manipulation in some cases. Standard lymph node dissection was carried out in $60 \%$ of cases and extended lymph node dissection in $40 \%$. An average of 14.6 lymph nodes were harvested. Early enteric feeding (2nd to 4 th post op day) was employed in $58 \%$. The leak was noted at median postoperative period of 6 days. The average amount of leak in the initial days was $870 \mathrm{ml} /$ day(range $260-3000 \mathrm{ml} /$ day). Most of the patients were managed conservatively with NPO, octreotide and in some cases TPN. This was followed by medium chain or low chain triglycerides oral intake, once the amount of leak reduced. Diagnostic paracentesis, lymphiscintigraphy, lymphangiogram, 
re-exploration and ligation of leaking lymphatic vessels andperitoneal venous shunt were carried out in limited number of cases. Associated post operative complications included pancreatic fistula, intra-abdominal abscess, sepsis, portal vein thrombosis, delayed gastric emptying. The mean time of discharge was 15 days post surgery.

\section{Discussion}

Diagnosis- Unfortunately, there is no consensus as to what constitutes a chylous leak and the parameters like the amount of milky white drainage and the triglyceride level in the drainage fluid to establish the diagnosis, vary [1-10]. This is reflected in table 1. Absence of clarity, effects the result in terms of its incidence, outcome and hence its assessment1. Chyle leak is defined by some, as any volume of milky appearance fluid, with triglyceride conc $>110 \mathrm{mg} / \mathrm{dl} 10$, as $100 \mathrm{ml} /$ day or more of milky, amylase free peritoneal fluid6, $>600 \mathrm{ml}$ of amylase poor chylous fluid3, chylous fluid with triglyceride concentration of $110 \mathrm{mg} / \mathrm{dl}$ or $1.2 \mathrm{mmol} / \mathrm{L}$ or more6. A chyle leak (CL) is a local peripancreatic chyle collection in contrast to chylous ascites (CA), which is defined by the presence of diffuse chyloperitoneum2. In most studies, chyle leak and diffuse chylous ascites are combined during reporting into a composite group to attain statistical power and this may jeopardize the detection of true differences in the outcome between the two1. In addition, in patients who have concurrent pancreatic/biliary anastomosis leak, it may be difficult to detect mild chyle leak, as the activated pancreatic enzymes may interfere with triglyceride estimation and bile may alter the milky white appearance of chyle, by staining it [1-4].

\section{When does chylous leaks/ascites (CLA) occur?}

The reported incidence and risk factors of CLA is variable. These are recognized complications following abdominal, urological and retroperitoneal surgery, but are barely reported15-18. Among the non-surgical causes, they are often associated following lymphatic disruption due to cirrhosis, neoplastic, infectious and inflammatory conditions [1-4]. The pathology could be variable. The leakage of chyle could be 1) due to obstruction of lymphatics at the base of mesentry, due to any cause, resulting inleakage from dilated lymphatics from the walls of bowel or mesentry, ii) lymphoperitoneal fistula usually associated with abnormal retroperitoneal lymphatic vessels; 3 ) retroperitoneal megalymphatics with or without fistula [9]. CLA as sequelae to surgery, usually accompanies retroperitoneal lymph node dissection [17], abdominal aortic aneurysm repairs16,19, splenorenal shunts20, liver transplantation $[6,21]$ and pancreatectomies1-10. It has been reported to occur in $1 \%$ of patients following hepatopancreaticobiliary (HPB) surgery, similar to the incidence following abdominal aortic surgery6. The incidence of CLA following pancreatic surgery is reported to range from 0.1 to $12 \%$ [1-10] and following liver transplantation in about 7\%6. It is reported to occur in 1.8 to $11 \%$ following pancreaticoduodenctomy $[1-5,7-10]$ compared to $0.1-12 \%$ following distal pancreatectomy2,6.However, in one of the largest series of 3,532 cases of pancreatectomy, the incidence of CLA was noted to be $1.3 \% 2$.

\section{Why does CLA occur?}

CLA following liver and bile duct surgery has been attributed to the inadvertent injury to the lymphatics in the hepatoduodenal ligament and the increased hydrostatic pressure following hepatectomy. Significant amount of lymph normally flows from liver through the hepatoduodenal ligament lymphatics, and following lymphatic disruption, chyle leak is a likely outcome $[6,22]$. However,only a small number of patients develop CLA post hepatectomy and hence the addition of other procedures including retroperitoneal dissection, caudate lobe resection and bile duct division may be contributing factors6. CLA is seen more often after liver transplantation, particularly in the presence of cirrhosis. Increased portal pressure and dilated porta hepatis and retrohepatic lymphatics, which are invariably disrupted following removal of native liver during transplant are believed to be the main contributing factors for developing CLA6. In one of the reports where CLAoccurred postcirrhosis related liver transplantation, the portal pressure was found to be $35 \mathrm{~cm} \mathrm{H} 20$ or above during surgery6.

The chyle leak post pancreaticoduodenectomy is related to the close proximity of cisterna chyli to the head of pancreas, anterior to the first and second vertebra [1-4]. Those patients who develop chylous leak post distal pancreatectomy, oftenundergone aortocaval lymphadenectomy [2, 4, 9]. Several factors during pancreatic surgery have been reported to independently increase the risk of developing CLA1-11. These include, the number of lymph nodes harvested andthe concomitant vascular resection and reconstruction [1-7](table1). The number of metastatic nodes, among the resected nodes are also reported to be a influencing factor $[1,4]$ though in some reports the opinion differed $[2,10]$. The risk of lymphatic disruption is most likely to occur in those patients who undergo skeletalisation of the superior mesenteric vessels with the potential risk of disruption of perivascular lymphatic channels [2-5]. For similar reasons, manipulation of the para-aortic area, and extensive dissection in those with retroperitoneal invasion, enhances the risk of developing CLA1$4,9,10$. While the above factors for lymphatic duct disruption are related to the extent of radical resection in malignancy2-11, in patients with chronic pancreatitis, it is the degree of surrounding inflammation and fibrosis, and hence the need for more extensive surgery that forms the contributing factor1. Long standing inflammatory process in chronic pancreatitisis also believed to cause congestion of lymph with subsequent lymph duct enlargement with a greater risk of being disrupted1. Female gender and chronic pancreatitis have been reported as predominant factors for developing CLA in one series1. Despite the inherent risk of developing CLA in these subgroup of patients, the overall absolute risk remains low.

The association of the above mentioned factors, in contributing to CLA is reported in several studies1-4,9-11. Increasing operative time of pancreatic resection was also reported to be predictive of increased chyle leak1. Interestingly, for every $30 \mathrm{~min}$ of increased operative time, a 14\% increased risk of developing postoperative chyle leak was noted(OR=1.14, 
Table 1: Literature Review : Chyle leak post pancreatic resection: Management and outcome.

\begin{tabular}{|c|c|c|c|c|c|c|c|c|}
\hline Series & $\begin{array}{l}\text { Day } \\
\text { of } \\
\text { Leak } \\
\text {-Median } \\
\text { Range( ) }\end{array}$ & $\begin{array}{l}\text { Amount } \\
\text { Of leak } \\
\text { ml/day } \\
\text { (range) }\end{array}$ & $\begin{array}{l}\text { Factors } \\
\text { Contributing } \\
\text { To leak }\end{array}$ & $\begin{array}{l}\text { Complications } \\
\text { Anl, BiL, Pvt , Pbl }\end{array}$ & $\begin{array}{l}\text { Management } \\
\text { Conservative } \\
\text { Diet TPN Octr }\end{array}$ & $\begin{array}{l}\text { Management } \\
\text { Surgical }\end{array}$ & Mort & $\begin{array}{l}\text { Mean } \\
\text { Hospital } \\
\text { Stay }\end{array}$ \\
\hline $\begin{array}{l}\text { Ji W et } \text { al }^{5} \\
2014\end{array}$ & $\begin{array}{l}6 \\
(5-8)\end{array}$ & $\begin{array}{l}355 \\
(260-450)\end{array}$ & & Nil & 23 & Nil & 0 & $\begin{array}{l}12 \\
(7-16)\end{array}$ \\
\hline $\begin{array}{l}\text { Hilal MA } \\
2013\end{array}$ & $2-5$ & NA & $\begin{array}{l}\text { Extent of LND } \\
\text { Pvt } \\
\text { EFeed }\end{array}$ & $\begin{array}{l}\text { Pvt=7.5\% } \\
\text { GI lk=10\% } \\
\text { Pbl=5\%, }\end{array}$ & $\begin{array}{l}\text { MCT feed via NGT/ } \\
\text { pj and then oral } \\
\text { MCT }\end{array}$ & Nil & 0 & $\begin{array}{l}15 \\
(7-60)\end{array}$ \\
\hline $\begin{array}{l}\text { Kuboki S et }{ }^{6} \\
\text { alal2 } 2013\end{array}$ & NA & NA & $\begin{array}{l}\text { EFeed- 10(59\%) } \\
\text { MnparaA } \\
\text { VascRes, RpIn }\end{array}$ & & $\begin{array}{l}\text { Oct }=\text { (output } \\
\text { decrease }- \text { median } 1 \\
\text { day }(1-2) \\
\text { TPN alone(median } \\
6(1-20 \text { days })\end{array}$ & Nil & 0 & NA \\
\hline $\begin{array}{l}\text { Kim JK }{ }^{10} \\
2013\end{array}$ & $\begin{array}{c}5 \\
(3-9)\end{array}$ & 443 & $\begin{array}{l}\text { Old age } \\
\text { Early enteral feed } \\
\text { Short operation time } \\
\text { Soft pancreas } \\
\text { texture<T2 stage }\end{array}$ & $\begin{array}{l}\mathrm{PF}=16.7 \% \\
\mathrm{DGE}=12.5 \%\end{array}$ & $\begin{array}{l}\text { TPN-12 } \\
\text { Diet control-4 } \\
\text { Recovered with no } \\
\text { specific treatment- } 8\end{array}$ & Nil & 0 & NA \\
\hline $\begin{array}{l}\text { Aoki H }{ }^{9} \\
2010\end{array}$ & $\begin{array}{c}8 \\
(6-16)\end{array}$ & 1100 & NA & NA & $\begin{array}{l}\text { TPN } \\
\text { Oct= (100ug-bd- } \\
\text { intramuscular) }\end{array}$ & Nil & 0 & 60 \\
\hline $\begin{array}{l}\text { Van der Gaag }{ }^{1} \\
2008\end{array}$ & $\begin{array}{l}6 \\
(3-52)\end{array}$ & $\begin{array}{l}600 \\
(400-963)\end{array}$ & $\begin{array}{l}\text { Chronic } \\
\text { Pancreatitis } \\
\text { Female }\end{array}$ & NA & $\begin{array}{l}\mathrm{LCT}=47 \\
\mathrm{TPN}=3 \\
\text { Diag-perct=3 } \\
\text { Expectant=16 }\end{array}$ & Nil & 0 & $\begin{array}{l}15 \\
(12-18)\end{array}$ \\
\hline $\begin{array}{l}\text { Assumpcao L } 2 \\
2008\end{array}$ & $\begin{array}{l}5 \\
(4-8)\end{array}$ & NA & $\begin{array}{l}\text { Extent of } \mathrm{LND} \\
\mathrm{CL}=18 \text { nodes (mean) } \\
\mathrm{CA}=19 \text { nodes }(\text { mean }) \\
\text { VascRes- } \mathrm{CL}=8.8 \% \\
\text { VascRes }=\mathrm{CA}=30.8 \%\end{array}$ & $\begin{array}{l}\mathrm{PF}=4.3 \% \\
\text { Pert }=6.4 \% \\
\text { Seps }=12.8 \% \\
\text { Absc }=4.3 \%\end{array}$ & $\begin{array}{l}\text { TPN-CL }=44.1 \% \\
\text { TPN-CA=92.3\% } \\
\text { Octr }=17 \%\end{array}$ & $\begin{array}{l}\text { Lscint }=10 \% \\
\text { Lgram }=6.4 \% \\
\text { Rxlig }=6.4 \%\end{array}$ & 0 & $\begin{array}{c}13 \\
(10-17)\end{array}$ \\
\hline $\begin{array}{l}\text { Mallik HZ3 } \\
2007\end{array}$ & $\begin{array}{l}6 \\
(5-9)\end{array}$ & $\begin{array}{l}1900 \\
(1400- \\
-3000)\end{array}$ & EFeed (57\%) & NA & $\begin{array}{l}\text { TPN }=100 \% \\
\text { Oct }=(100 \%) \\
(5 \text { days post op })\end{array}$ & PV shunt=1 & 0 & NA \\
\hline & $\begin{array}{l}6 \\
(2-52)\end{array}$ & $\begin{array}{l}870 \\
(260- \\
(260-3000)\end{array}$ & ---- & ---- & ---- & ---- & - & --- \\
\hline \multicolumn{9}{|c|}{$\begin{array}{l}\text { AnL- anastomotic leak, } \mathrm{BiL}=\text { bile leak, Pvt=portal vein thrombosis, } \mathrm{Pbl}=\text { postoperative bleeding, } \mathrm{TPN}=\text { total parenteral nutrition, } \mathrm{Octr}=\mathrm{octreotide} \\
\mathrm{MCT}=\text { medium chain Triglyceride, } \mathrm{LND}=\text { lymph node dissection, MnparaA= manipulation of para-aortic region, VascRes=vascular resection, } \mathrm{RpIn=} \\
\text { retroperitoneal invasion, } \mathrm{PF}=\text { pancreatic fistula, } \mathrm{DGE}=\text { delayed gastric emptying, Diag-perct= diagnostic paracentesis, Pert= peritonitis, Seps=sepsis, } \\
\text { Absc=abscess, } \mathrm{CL}=\text { chylous leak, } \mathrm{CA}=\text { chylous ascites, Lscint=lymphoscintigraphy, Lgram=lymphangiogram, Rxlig= re-exploration and ligation of } \\
\text { lymphatic vessel, Efeed=early enteral feeding, PV shunt= peritoneovenous shunt. }\end{array}$} \\
\hline
\end{tabular}

95\% CI 1.02-1.28; $\mathrm{p}=0.01$ )1. The increasing number of lymph nodes harvested was another factor and the median total number of lymph nodes removed in patients developing a chyle leak was 18 compared with 16 in control group( $\mathrm{p}=0.06) 1$.For each individual lymph node harvested, the risk of chyle leak increased by $6 \%(\mathrm{OR}=1.06,95 \% \mathrm{CI}, 1.01-1.11 ; \mathrm{p}=0.01) 1$. A greater percentage of patients who developed CLA underwent surgery with intent of radical lymphadenectomy $(22.5 \%)$ vs $6.8 \%$ in the non-chylous group; $(\mathrm{p}=0.001) 4$. Vascular resection with reconstruction was a factor that was strongly associated with the risk of chyle leak(OR=4.81, 95\% CI 1.41-16.6;p=0.01)1. However in another study a statistical difference was not seen between the chylous and non-chylous group, post resection of vein and reconstruction4. Intraoperative blood loss was also not different, between the 2 groups 4 .

Several reports indicate thatpostoperative factors too couldincrease the risk of developing CLA, namely the early enteric feeding [1-4, 9]. Following the ingestion of fatty meal, fat absorption from the diet, significantly increases the lymphatic flow in the cisterna chyli, from a fasting baseline of $<1 \mathrm{ml}$ to 


\begin{tabular}{|c|c|c|c|c|c|c|c|c|c|c|c|c|}
\hline $\begin{array}{c}S \text { series } \\
\text { year }\end{array}$ & $\begin{array}{l}\text { No of } \\
\text { Pts. } \\
\text { with } \\
\text { PanS }\end{array}$ & $\begin{array}{l}\text { Def. } \\
\text { Of } \\
\text { CL }\end{array}$ & $\begin{array}{l}\text { No (\%) } \\
\text { with } \\
\text { CL/CA }\end{array}$ & $\begin{array}{r}\text { Operation } \\
\text { PDs -PDp } \\
\text { No } \\
(\%)\end{array}$ & TP- DP & $\begin{array}{r}\text { Lymph } \\
\text { Dissec } \\
\text { SNL E } \\
\text { N } \\
\text { (\% }\end{array}$ & $\begin{array}{l}\text { node } \\
\text { tion } \\
\text { LN } \\
\text { ) }\end{array}$ & $\begin{array}{l}\text { No of } \\
\text { Nodes } \\
\text { removed } \\
\text { Avg } \\
\text { (range) }\end{array}$ & $\begin{array}{l}\text { VR } \\
\text { No(\%) }\end{array}$ & $\begin{array}{l}\text { VisR } \\
\text { No } \\
\text { (\%) }\end{array}$ & R0 NonR0 & $\begin{array}{l}\text { Day of } \\
\text { Enteral } \\
\text { feed }\end{array}$ \\
\hline $\begin{array}{l}\text { Ji W et al } \\
2014\end{array}$ & 381 & * & $\begin{array}{l}23 \\
(0.6)\end{array}$ & $78 \quad 303$ & $\begin{array}{ll}-0 & -0\end{array}$ & NA & NA & NA & 0 & NA & $\begin{array}{l}4(17.4) \\
19(82.6)\end{array}$ & NA \\
\hline $\begin{array}{l}\text { Hilal MA } \\
2013\end{array}$ & 245 & $* *$ & $\begin{array}{l}40 \\
(1.6 .3 \%)\end{array}$ & $\begin{array}{ll}37 & -0 \\
(92.5) & --(7\end{array}$ & $\begin{array}{ll}-3 & -0 \\
7.5) & \end{array}$ & $\begin{array}{l}31 \\
(77.5)\end{array}$ & $\begin{array}{c}9 \\
(22.5)\end{array}$ & $\begin{array}{l}17.6 \\
(6-46)\end{array}$ & $\begin{array}{l}10 \\
(25 \%)\end{array}$ & $\begin{array}{l}5 \\
(12.5 \%)\end{array}$ & NA & $\begin{array}{l}1^{\text {st }} \text { postop } \\
\text { polymeric } \\
\text { or semi- } \\
\text { elemental } \\
\text { tube diet }\end{array}$ \\
\hline $\begin{array}{l}\text { Kuboki S } \\
2013\end{array}$ & 574 & *** & $\begin{array}{c}17 \\
(3.2 \%)\end{array}$ & $11-1$ & $-0-5$ & NA & & $\begin{array}{l}13 \\
(\mathrm{NA})\end{array}$ & $\begin{array}{c}9 \\
(53 \%)\end{array}$ & $\begin{array}{c}13 \\
(76 \%)\end{array}$ & NA & $\begin{array}{l}\text { Early } \\
\text { enteral } \\
\text { feed- } \\
10(59 \%)\end{array}$ \\
\hline $\begin{array}{l}\operatorname{Kim~JK}^{10} \\
2013\end{array}$ & 222 & $* * * *$ & $\begin{array}{c}24 \\
(10.8 \%)\end{array}$ & $60-162-$ & $0-\quad 0$ & $\begin{array}{l}10 \\
(41.6)\end{array}$ & $\begin{array}{r}14 \\
(58.4)\end{array}$ & $18.7 \pm 14.9$ & NA & NA & NA & $2.3 \pm 1.0$ \\
\hline $\begin{array}{l}\text { Aoki } H^{9} \\
2010\end{array}$ & 65 & *\# & $\begin{array}{c}5 \\
(7.7 \%)\end{array}$ & 0 - & $0-25$ & $\begin{array}{c}3 \\
(60 \%)\end{array}$ & $\begin{array}{c}2 \\
(40 \%)\end{array}$ & NA & NA & NA & NA & 1-2 days \\
\hline $\begin{array}{l}\text { van der Gaag }{ }^{1} \\
2008\end{array}$ & 440 & **\# & $\begin{array}{c}66 \\
(11 \%)\end{array}$ & $-56-$ & $0-0$ & NA & & 7 & NA & NA & $\begin{array}{lc}40 & 12 \\
(77) & (23)\end{array}$ & NA \\
\hline $\begin{array}{l}\text { Assumpcao } L^{2} \\
2008\end{array}$ & 3532 & **\# & $\begin{array}{c}47 \\
(1.3 \%) \\
\operatorname{CL}(34) \\
\operatorname{CA}(13)\end{array}$ & 6- 24 & $-1-0$ & NA & & $\begin{array}{l}\text { CL-18 } \\
(12-24) \\
\text { CA- 19 } \\
(14-22)\end{array}$ & $\begin{array}{l}\text { CL-3(8\%) } \\
\text { CA- } \\
4(30 \%)\end{array}$ & NA & NA & NA \\
\hline $\begin{array}{l}\text { Mallik HZ } \\
2007\end{array}$ & 105 & **\#\# & $\begin{array}{l}7 \\
(6.7 \%)\end{array}$ & $105-0$ & $\begin{array}{ll}0 & -0\end{array}$ & NA & & NA & NA & NA & NA & $4(57 \%)$ \\
\hline & 5564 & & $\begin{array}{l}229 \\
4.11 \%\end{array}$ & 307- 546 & $\begin{array}{ll}-4 & -25\end{array}$ & $60 \%$ & $40 \%$ & 14.6 & $36 \%$ & $44 \%$ & -- & $58 \%$ \\
\hline \multicolumn{13}{|c|}{$\begin{array}{l}\text { *.sudden increase in volume of intraperitoneal drainage fluid(milky white or pale yellow) or chylous test was positive after taking food for } 1 \text { or } 2 \text { day } \\
\text { **milky appearance of drain fluid at volumes greater than } 200 \mathrm{ml} / \mathrm{day} \text {. When CL diagnosis was equivocal despite suspicion, the presence of drain flu } \\
\text { triglyceride concentration twice that of serum and }>1.5 \mathrm{mmol} / \mathrm{L}(131 \mathrm{mg} / \mathrm{dl}) \\
\text { *** } 100 \mathrm{ml} \text { or more /day of milky amylase free peritoneal fluid with a triglyceride concentration of } 110 \mathrm{mg} / \mathrm{dl} \text { or above } \\
\text { **** any drainage volume with a milky appearance and triglyceride conc of }>110 \mathrm{mg} / \mathrm{dl} \\
\text { *\#- secretion of milky white fluid with high triglyceride content } \\
\text { **\# - drain output with likely appearance, concurrent with the start of enteral feeding with triglyceride concentration }>1.2 \mathrm{mmol} / \mathrm{L} \\
\text { **\#- drainage more than } 600 \mathrm{ml} \text { of amylase - poor chylous fluid per day } \\
\text { Pts= patients, PanS= pancreatic surgery, VR= vein and/or artery resection, CL= chyle leak, CA=chyle ascites, PDs=pancreaticoduodenectomy, PDp= } \\
\text { pylorus preserving pancreaticoduodenectomy, T= total pancreatectomy, DP= distal pancreatectomy, SNL= standard lymph node dissection, ELN= } \\
\text { extended lymph node dissection, } \mathrm{NA}=\text { not available }\end{array}$} \\
\hline
\end{tabular}

$225 \mathrm{ml} / \mathrm{min} 9$. Several reports suggest the association of early enteric feeding and the incidence of CLA1-4,9,10. In one of the reports, enteral intake was started on $2.3 \pm 1.0$ in patients who developed chyle leak, in sharp contrast of $4.6 \pm 3.7$ days in patients without chyle leak [10]. Chylous leak is reported in $57 \%$ of patient with chylous leak in contrast to $35 \%$ in patients without chylous leak [3]. This increase risk in patients with early enteral feed is attributed to the leak of chyle through the disrupted lymphatics, before it had time to heal. Postoperative complications such as leak from biliary, pancreatic, gastrointestinal anastomosis, intra-abdominal abscess, intra-abdominal bleeding, delayed gastric emptying, wound dehiscence,when studied as potential independent risk factors for developing CLA,failed to show any relationship; the only exception to this being those patients who developed portal/mesenteric venous thrombosis4. The incidence of CLA was $7.5 \%$ in those who developed portal/mesenteric thrombosis compared to $1.5 \%$ in those without CLA ( $p=0.02)$ [4].

\section{Intraoperative measures to detect and reduce the risk of leak}

Investigators have considered the possibility of detecting these leaks early in its course of its occurrence, as during surgery. This method of intraoperative detection of leak is achieved by delivering fat containing fluid into the duodenum and looking for evidence of leak during surgery. This has been performed by administrating $60 \mathrm{gm}$ of butter, $4 \mathrm{~h}$ before surgery [23] or by injecting during surgery, $50 \mathrm{ml}$ of $10 \%$ intralipid into jejunum, just prior to its division [3] or by delivering $100 \mathrm{ml}$ of milk through NG tube into the duodenum, after its mobilization during Kocherisation9. In the presence of chyle leak, white milky 
discharge is noted in 2-3 $\mathrm{h}$ after milk injection [9]. The milk test is reported to detect the leak on the table and also reduce the incidence of postoperative CLA from $7.7 \%$ in those who did not undergo the test to $2.9 \%$ in those who underwent [9]. Once detected during surgery, the leak is prevented from occurring by applying the basic principle of careful ligation and clipping of these leaking lymphatic channels [9]. Dissection is often carried by some using Harmonic scalpel [3, 24]. Unfortunately, even the use of harmonic scalpel does not necessarily prevent the development of lymphatic fistula $[3,24]$. Hence, the milk test is reported to facilitate the detection of leak on table and enable meticulous control of these,by ligation under direct vision. Majority of the leak (95.7\%) are believed to occur around the periphery of SMV/SMA3. Milk test, with its inherent advantage of being easy to carry out, inexpensive, safe, is recommended by some to be carried out in patients at a high risk of developing CLA post pancreatic resections [3].

\section{Grading system for isolated chylous ascites after pancreaticoduodenectomy}

van der Gaag et al have proposed a grading system using various parameters including clinical condition, signs of infection, ultrasound/CT findings, duration of chylous drainage to less than 7 days or more than 14 days, dietary measures, persistent drainage, surgical intervention, prolonged hospital stay and readmissions [1]. Three grades (A, B, C) have been proposed1. Grade A: there is either no or minimal deviation in the clinical course, as the leak is detected only biochemically, without any significant clinical presentation. This grade is managed with low chain triglyceride (LCT) diet and should not be associated with prolonged drainage or hospital stay. Grade B: this is associated with prolonged duration of CLA leak, persistent drainage and longer duration of hospital stay. Grade $\mathrm{C}$ is reserved for patients, who have one or more of the following findings: chylous drainage lasting for more than 2 weeks, despite therapeutic measures, requirement of TPN or surgical intervention or both and readmission due to chylous ascites development1. In their series of 54 cases of CLA, the percentage of grade A, grade B and grade C were $31(57 \%), 15(27.7 \%)$ and $8(14.8 \%)$ respectively [1]. This grading system may help in assessing the outcome and response to treatment based on the severity of CLA.

\section{How are these patients managed?}

\section{Conservative}

The conservative management is the mainstay in the treatment and the most prudent initial approach [1-11]. It comprises of administration of octreotide, combined with fasting. TPN and adequate paracentesisare advocated when required [1$7,9]$. This has to be balanced with careful fluid monitoring with supplemented intravenous rehydration. Octreotide achieves its goal of reducing chyle, by decreasing the splanchnic blood flow and portal pressure and reducing the intestinal absorption of fat and hence reduces the lymph flow in the major lymphatic channels [15]. This is reported to achieve a sharp reduction in chylous drainage and shortened hospital stay and hence the medical costs [2-7]. Some are so convinced of its role that they recommend its use prophylactically [15], though others differ in their opinion [1].In one major study, patients who received octreotide treatment had a reduction of chyle drain below $100 \mathrm{ml}$ within a median period of 1 day (1-2) versus 6(1-20) days in those who were treated with TPN alone6.Moreover, the octreotide treated group resumed oral intake significantly earlier(median 7(5-14) versus 15(7-22) days in TPN alone group;p=0.004. In addition, the abdominal drains were removed significantly earlier, median 12(3-19) versus 19 (11-40) days $p=0.018$, in the TPN alone group6. Reduction of drainage below $100 \mathrm{ml} /$ day should be followed by high protein and oral medium chain triglyceride (MCT) or low chain triglyceride (LCT) diet [1-7, 9]. Theseare likely to be absorbed by enterocytes and transported as free fatty acid and glycerol directly to the liver via the portal circulation rather than through the lymphatics15. Patients are maintained on MCT/LCT until the drain output has ceased [1$4,9]$. While it may not be advisable to restrict earlyoral intake of normal diet in all patients who have undergone pancreatic resections, there are some who suggest selective policy of restricting normal oral diet and replacing it with pre-emptive MCT/LCT diet in those patients who are perceived to be at "high risk" of developing CLA [2,4]. These include those with extensive lymph node and retroperitoneal dissection, skeletonisation of superior mesenteric vessels and portal/mesenteric vein thrombosis $[1-7,9]$. TPN is often not needed, but may be required in those patients who are unable to tolerate oral (delayed gastric emptying) or in those in whom nutritional requirements cannot be met by mere oral intake. TPN is continued until the chyle leak has clinically resolved and patient tolerates a period of $24 \mathrm{~h}$ of enteral nutrition, without recurrence of the leak [3]. In one of the reports, TPN was used for a median period of 7.5 days(mean 10.7 days), when complications did not occur [3].The obvious drawback of TPN however is its cost, a need for dedicated central venous catheter with a potential risk of infection and failure to maintain intestinal mucosal integrity, which needs enteral feeding [1]. Paracentesis is rarely required and its need is usually for diagnostic/therapeutic reason, when an abdominal drain is not present [1]. It however may offer an immediate palliative effect in patients with chylous ascites. Diagnostic laparoscopy has been carried out by some, to investigate the leak in chylous ascites and to place a drain [23]. Chyle leak is reported to be detected between 4 to 8 days(median 5 days) [2] and in another study 3-52 days (median 6 days) [1]. This would depend to a large extent on the time of commencement of oral intake [1, 2, $9,10]$.Some have investigated for a potential warning signal of chyle leak and have noted that a drainage volume of $>335 \mathrm{ml}$ on the 4 th postoperative day is indicative of leak, with a sensitivity of $79.17 \%$ and specificity of $62.7 \%$ )[10]. In patients who are refractory to all the above measures and who are not keen or fit for surgical intervention, an option of radiotherapy has recently been reported [11].

\section{Surgical}

The reported success following conservative management is 
60 to $100 \% 3$. The patients, who fail conservative management, may require more aggressive therapeutic approach, which includes lymphoscintigraphy, lymphangiogram, sclerotic therapy or reoperation [1-7]. Lymphoscintigraphy and lymphangiogram are considered by some in defining the site of lymphatic leak2. However, the efficacy of these studies in postoperative setting is ill defined [25]. In one of the report where these investigations were carried out, lymphoscintigraphy was successful in detecting leak in 1 out of $4(25 \%)$ and lymphangiogram in 1 out of $3(33 \%)$ of the cases.In cases were leak is detected, sclerotic embolization of the leak site is an option2.In intractable cases, surgical intervention may be required to detect the leak and directly suture it [2-5]. Unfortunately, this is rarely successful following re-exploration, and in one series it was unsuccessful in all the 3 cases attempted [2]. Failure to do so may warrant a placement of peritoneovenous shunt [2-4]. However, in view of the potential complications that are associated with peritoneovenous shunting, including fluid shifts, electrolyte imbalance, sepsis and shunt occlusion, it should be used judiciously.

\section{Radiotherapy}

Radiotherapy has been reported recently to having been used successfully in a patient who had a high output chylous leak of $2500 \mathrm{ml}$ per week, despite being on TPN, octreotide and NPO for 4 weeks [11]. Control of fistula was successfully achieved with external beam radiotherapy to the para-aortic region of $8.0 \mathrm{~Gy}$, in daily fraction of 1.0Gy (5 fraction per week). Hence radiotherapy could be considered as an option for very refractory cases [11].

\section{Factors determining the outcome}

\section{Morbidity and mortality}

Some studies reveal no undue additional morbidity or mortality in patients, who developed CLA once the conservative measures was implemented [2]. While CLA is likely to be associated with longer duration of abdominal drainage, less likelihood of discharge within 10 days of surgery, the overall hospital stay, duration of ITU/HDU level care, the need for nasogastric intubation and overall time for resumption of normal oral intake was not significantly effected. However, several reports document, complications [2, 4].Complications associated with chyle leak included abscess (4.3\%), concomitant pancreatic fistula (4.3\%), malnutrition (eg albumin $<3.5 \mathrm{mg} / \mathrm{dl}$ ) 91.5\%, peritonitis (6.4\%) and sepsis (12.8\%) [2]. In another study, the most frequent complication was hospital acquired pneumonia (29.8\%), intra-abdominal collection/abscess (25.7\%) and delayed gastric emptying (18.4\%) [4], though a difference in these complications between chylous and non-chylous group was not observed4.

Investigators have tried theanalyze the difference with regards to natural history and prognostic implications between patients who develop contained chylous leak and those who develop diffuse chylous ascites [2]. These differences were found to be dramatically different. This was reflected by the fact that contained chyle leaks frequently resolved after a short duration of conservative management (median 5 days)while patients who have chylous ascites had a much more protracted clinical course (median 36 days) [2]. Not surprisingly, patients who developed chylous ascites were likely to fail conservative management and needed additional therapeutic interventions ( eg lymphoscintigraphy, lymphangiogram or re-operation) [2]. In one of the reports, $2.9 \%$ with localized chylous leak failed conservative management in contrast to $46.2 \%$ in patients with chylous ascites $(\mathrm{p}=0.004)$ [2].Overall, the median time to resolution of the chyle leak was 13 days (8-27 days). For those patients managed conservatively (eg TPN), the chyle leak resolved within a median of 15 days (9-28 days range) in contrast to a median of 58 days (16-232 days range) in those that required more aggressive management (eg lymphoscintigraphy, lymphangiogram or reoperation)[2]. A significant difference in the overall survival was also noted. None of the patients who developed chylous ascites post resection for adenocarcinoma were alive at 18 months. In another report the 3-year survival of patients with chylous ascites with $18.8 \%$ compared to $53.4 \%$ in patients with contained chyle leak [2].Hence it has been reported that chyle leak post pancreatic resection may have short natural history and no impact on long term outcome while diffuse chylous ascites in addition to being associated with prolonged clinical course is also associated with increased mortality in those following resection for adenocarcinoma.

\section{Conclusion}

Chyle leak, post pancreatic resection is being reported off late. The possible increased incidence could be due to a combination of more aggressive surgical resection, including extended lymphadenctomy and vascular resection and reconstruction. Attempts are being made to detect them intra-operatively in highrisk patients by delivering fat rich nutrients into the gut during the surgery. Most of the chyle leak can be managed conservatively with NPO, octreotide and TPN. However, in a small percentage of cases, more aggressive intervention including lymphoscintigrapy, use of sclerosant, direct ligation of leaking lymphatic channels and peritoneovenous shunts may be required. Successful control of refractory chylous has recently been achieved with radiotherapy. Being aware of this complication helps in prompt diagnosis and treatment which in turn could reduce the risk of complication and hospital stay.

\section{References}

1. van der Gaag NA, Verhaar AC, Haverkort EB, Busch OR, van Gulik TM, Gouma DJ. Chylous ascites after pancreaticoduodenectomy: introduction of a grading system. J Am Coll Surg. 2008;207(5):751757.

2. Assumpcao L, Cameron JL, Wolfgang CL, Edil B, Choti MA, Herman JM, et al. Incidence and management of chyle leaks following pancreatic resection: a high volume single-center institutional experience. J Gastrointest Surg 2008;12(11):1915-1923. doi: 10.1007/s11605008-0619-3.

3. Malik HZ, Crozier J, Murray L, Carter R. Chyle leakage and early enteral feeding following pancreaticoduodenectomy: managementoptions. Dig Surg. 2007;24(6):418-422. 
4. Abu Hilal M1, Layfield DM, Di Fabio F, Arregui-Fresneda I, Panagiotopoulou IG, Armstrong TH, et al. CD Postoperative chyle leak after major pancreatic resections in patients who receive enteral feed: risk factors and management options.World J Surg. 2013 Dec;37(12):2918-2926. doi: 10.1007/s00268-013-2171-x.

5. Ji W, Wang J, Song B, Zheng K, Ma H, Nadaf A, et al. Cause analysis and therapeutic methods of chylous leakage after pancreaticoduodenectomy. Saudi Med J. 2014;35(11):1396-1399.

6. Kuboki S, Shimizu H, Yoshidome H, Ohtsuka M, Kato A, Yoshitomi H, et al. Chylous ascites after hepatopancreatobiliary surgery.Br J Surg 2013;100(4):522-527. doi: 10.1002/bjs.9013.

7. Kollmar O, Schilling MK, Buuchler MW. Treatment of chyloperitoneum after extended lymphatic dissection during duodenopancreatectomy Int J Pancreatol.2000;27(1):83-87

8. Gallagher MC, Shankar A, Groves CJ, Russell CG, Phillips RKS. Pylorus preserving pancreaticoduodenectomy for advanced duodenal disease in familial adenomatous polyposis. Br J Surrg.2004;91(9):1157-1164

9. Aoki H, Takakura N, Shiozaki S, Matsukawa H. Milk based test as a preventive method for chylous ascites following pancreatic resection. Dig Surg. 2010;27(5):427-432. doi: 10.1159/000320692.

10. Kim JK, Park JS, Hwang HK, Shin HW, Yoon DS. Drainage volume after pancreaticoduodenectomy is a warning sign of chyle leakage that inversely correlates with a diagnosis of pancreatic fistula. World Surg.2013;37(4):854-862. doi: 10.1007/s00268-013-1919-7.

11. Corradini S, Liebig S, Niemoeller OM, Zwicker F, Lamade W. Successful radiation of chylous ascites following pancreaticoduodenectomy. Strahlenther Onkol.2015;191(5):448-452. doi: 10.1007/s00066-0140805-z. Epub 2015 Jan 10.

12. Aalami 00, Allen DB, Organ CH Jr. Chylous ascites: a collectivereview. Surgery. 2000;128(5):761-778.

13. Lemaire LC, van Lanschot JB, Stoutenbeek CP, van Deventer SJ, Dankert J, Oosting $\mathrm{H}$ et al. Thoracic duct in patients with multiple organ failure: no major route ofbacterial translocation. Ann Surg 1999;229(1):128-136.

14. Staats BA, Ellefson RD, Budahn LL, Dines DE, Prakash UB, Offord Ket al. The lipoprotein profile of chylous and nonchylous pleural effusions. Mayo ClinProc .1980;55(11):700-704.

15. Leibovitch I, Mor Y, Golomb J, Ramon J. The diagnosis and management of postoperative chylous ascites. J Urol. 2002;167(2 pt 1):449-457.

16. Combe J, Buniet JM, Douge C, Bernard Y, Camelot G, et al. [Chylothorax and chylous ascites following surgery of an inflammatory aortic aneurysm. Casereport with review of the literature]. JMal Vasc 1992;17(2):151-156

17. Evans JG, Spiess PE, Kamat AM, Wood CG, Hernandez M, Pettaway CA ,et al. Chylous ascites after postchemotherapy retroperitoneal lymph node dissection: review of theMD Anderson experience. J Urol. 2006;176(4 Pt 1):1463-1467.

18. Ablan CJ, Littooy FN, Freeark RJ. Postoperative chylous ascites: diagnosis and treatment. A series report and literature review.Arch Surg. 1990;125(2):270-273.

19. Busch T, Lotfi S, Sirbu H, Dalichau H. Chyloperitoneum: a rare complication after abdominal aortic aneurysm repair. Ann VascSurg. 2000;14(2):174-175

20. Edoute Y, Nagachandran P, Assalia A, Ben-Ami H. Transient chylous ascites following a distal splenorenal shunt. Hepatogastroenterology.2000;47(32):531-532.

21. Asfar S, Lowndes R, Wall WJ. Chylous ascites after livertransplantation. Transplantation. 1994;58:368-369.

22. Prabhakaran K, Vidyadhar M, Jahoorahmad P, Hwee Neo Grace T. Chylous ascites following liver resection - casereport. Pediatr Surg Int. 2004; 20(9): 719-721.

23. Campisi C, Bellini C, Eretta C, Zilli A, Rin E, Davini D, et al: Diagnosis and management of primary chylous ascites. J Vasc Surg. 2006;43(6):1244-1248.

24. Giovannini I, Giuliante F, Chiarla C, Ardito F, Vellone M, Nuzzo G.Nonsurgical management of a lymphatic fistula, after laparoscopic colorectal surgery, with total parenteral nutrition, octreotide, and somatostatin. Nutrition 2005; 21(10):1065-1067.

25. Pui MH,Yueh TC.Lymphoscintigraphyin chyluria, chyloperitoneumand chylothorax. J Nucl Med 1998;39(7):1292-1296. 